\title{
Subclinical Thyroid Function and Cardiovascular Events in patients with Atrial
} Fibrillation

Elisavet Moutzouri, MD PhD ${ }^{1}$, Christina Lyko, MD ${ }^{1}$, Martin Feller MD MSc${ }^{1}$, Manuel Raphael Blum MD MSc ${ }^{1,2}$, Luise Adam MD ${ }^{1,3}$, Steffen Blum, MD PhD ${ }^{4,5}$, Stefanie Aeschbacher $\mathrm{PhD}^{4,5}$, Urs Fischer, $\mathrm{MD} \mathrm{MS}^{6}$, Laurent Roten, $\mathrm{MD}^{7}$, Cinzia Del Giovane, $\mathrm{PhD}^{1}$, Christine S. Meyer-Zuern, MD,5, Giulio Conte ${ }^{8}$, Leo H. Bonati, MD ${ }^{9}$, Giorgio Moschovitis, $\mathrm{MD}^{10}$, Michael Kuehne, MD ${ }^{4,5}$, Juerg Beer, MD ${ }^{11}$, Drahomir Aujesky, MD MSc ${ }^{1,2}$, Stefan Osswald, MD ${ }^{4,5}$, David Conen, MD MPH ${ }^{4,5,12}$, Nicolas Rodondi, MD MAS ${ }^{1,2}$

\section{INSTITUTIONS:}

${ }^{1}$ Institute of Primary Health Care (BIHAM), University of Bern, Switzerland.

2 Department of General Internal Medicine, Inselspital, Bern University Hospital, Bern, Switzerland.

${ }^{3}$ Division of Angiology, Swiss Cardiovascular Center, Inselspital, Bern University Hospital, University of Bern, Switzerland

${ }^{4}$ Cardiology Division, Department of Medicine, University Hospital Basel, Basel, Switzerland

${ }^{5}$ Cardiovascular Research Institute Basel, Basel, Switzerland

${ }^{6}$ Department of Neurology, Inselspital, Bern University Hospital, University of Bern, Bern, Switzerland

${ }^{7}$ Division of Cardiology Department of Medicine Inselspital Bern University Hospital University of Bern Switzerland

${ }^{8}$ Center for Computational Modeling in Cardiology, Switzerland; Cardiocentro Ticino, Switzerland 
${ }^{9}$ Department of Neurology and Stroke Center, University Hospital Basel, University of Basel, Basel, Switzerland

${ }^{10}$ Cardiology Division, EOC Regional Hospital of Lugano, Lugano, Switzerland

${ }^{11}$ Department of Medicine, Cantonal Hospital of Baden and Center for Molecular Cardiology, University Hospital of Zurich, Zurich, Switzerland

12 Population Health Research Institute, McMaster University, Hamilton, Canada

\section{Corresponding author:}

Elisavet Moutzouri, MD PhD, Bern University Hospital, Switzerland, Tel +41 3163241 63;

Fax: + 413163288 85; Email: elisavet.moutzouri@extern.insel.ch

Short title: Cardiovascular disease and thyroid function

Word count: 3836 (only text from Introduction to Conclusion, without tables and figures) 


\section{Abstract}

Objective: To evaluate if subclinical thyroid dysfunction is associated with cardiovascular $(\mathrm{CV})$ risk in patients with atrial fibrillation $(\mathrm{AF})$.

Methods: Swiss-AF is a prospective cohort of community-dwelling participants aged $\geq 65$ years with AF. Primary outcome was a composite endpoint of CV events (myocardial infarctions, stroke/transitory ischemic events, systemic embolism, heart failure (HF) hospitalizations, CV deaths). Secondary outcomes were component endpoints, total mortality and AF-progression. Exposures were thyroid dysfunction categories, TSH and fT4. Sensitivity analyses were performed for amiodarone use, thyroid hormones use and competing events. Results: 2415 patients were included (mean age 73.2 years; 27\% women). $196(8.4 \%)$ had subclinical hypothyroidism and 53 (2.3\%) subclinical hyperthyroidism. Subclinical thyroid dysfunction was not associated with CV events, during a median follow-up of 2.1 years (max 5 years): age- and sex- adjusted hazard ratio (adjHR) of 0.99 (95\% confidence interval (CI) 0.69-1.41) for subclinical hypothyroidism; and 0.55 (95\%CI $0.23-1.32)$ for subclinical hyperthyroidism. Results remained robust following multivariable adjustment and sensitivity analyses. In euthyroid patients, fT4 levels were associated with an increased risk for the composite endpoint and HF (adjHR 1.46 95\%CI 1.04- 2.05; adjHR 1.70 95\%CI 1.08-2.66, respectively, for the highest quintile versus the middle quintile). Results remained similar following multivariable adjustment. Results remained significant for HF in sensitivity analyses. No association between subclinical thyroid dysfunction and total mortality or AFprogression was found.

Conclusions: Subclinical hypothyroidism was not associated with increased CV risk in AF patients. Higher levels of fT4 with normal TSH were associated with higher risk for HF. Key words: Thyroid; atrial fibrillation; cardiovascular outcomes, heart failure Word count: 248 words 


\section{Introduction}

Subclinical thyroid dysfunction, which includes subclinical hypothyroidism and subclinical hyperthyroidism (defined as elevated or decreased TSH, respectively, with fT3 and fT4 in the normal range) is frequent with subclinical hypothyroidism occurring in up to $12 \%$ among elderly and subclinical hyperthyroidism in up to $6 \%$ of the general population (1). Subclinical thyroid disease has been associated with an increased risk of coronary heart disease (CHD) events and cardiovascular (CV) mortality $(2,3)$ as well as with an increased risk of heart failure (HF) events, particularly for TSH levels $<0.1 \mathrm{mIU} / \mathrm{L}$ and $>10 \mathrm{mIU} / \mathrm{L}(4,5)$. The risk of stroke may also be increased in younger patients with subclinical hypothyroidism (6). Thyroid dysfunction is also associated with atrial fibrillation (AF) $(3,7-11)$, with a prevalence of up to $22 \%$ in hyperthyroid subjects (12) compared to $3 \%$ in the general population (13). Subclinical hyperthyroidism has been associated with a $>5$-fold increased AF risk (14). Furthermore, development of AF is an adverse effect of overtreatment of hypothyroidism (15) and higher circulating fT4 levels even in persons with normal TSH levels have been associated with increased AF risk and $\mathrm{HF}$ events $(8,16)$.

AF may be progressive and 3 types of AF are recognized in clinical practice: paroxysmal (AF that terminates spontaneously within 7 days), persistent (AF that does not terminate spontaneously within 7 days) or permanent AF (no rhythm control can be achieved) (17). Progression of paroxysmal or persistent to permanent AF has been associated with an increased risk of ischemic stroke, cardiac dysfunction and mortality (18-21). Previous data has found that history of hyperthyroidism may be a risk factor for AF-progression (Hazard Ratio (HR) 1.71; 95\% CI, 1.16-2.52) (18).

The association between thyroid dysfunction and adverse CV events in participants with established AF remains unclear (22-24). Previous studies have suggested that a history of 
hyperthyroidism in participants with AF represents an independent risk factor for stroke (22, $24)$, with conflicting results in other studies $(23,25)$. Subclinical thyroid dysfunction is a common diagnosis in patients with $\mathrm{AF}$ (26), and its association with stroke in the $\mathrm{AF}$ population has not been previously examined. In addition, AF population may differ substantially in comparison to the general population in terms of treatments as well as comorbidities and outcomes (27), making the investigation of the association between subclinical thyroid dysfunction and CV events and thus identification of modifiable risk factors particularly relevant. Furthermore, taking into account the direct cardio metabolic effects of thyroid hormones, it is not known whether thyroid dysfunction induces an AFprogression.

This study's primary aim was to examine if subclinical thyroid dysfunction was associated with higher $\mathrm{CV}$ risk and secondary if subclinical thyroid dysfunction is associated with total mortality or AF-progression in AF patients.

\section{Methods}

\section{The Swiss-AF}

The study protocol has been previously described (28). Swiss-AF is a prospective multicenter observational cohort study conducted in 14 centers in Switzerland (4 university hospitals and 10 cantonal hospitals). Main inclusion criteria were age $\geq 65$ years and AF. In addition, we aimed to enroll $10 \%$ to $15 \%$ of patients between 45 and 65 years of age to assess the effects of AF on individuals in the active workforce (29). Main exclusion criteria were inability to provide informed consent, the presence of exclusively non-sustained episodes of secondary AF or any acute illness in the last 4 weeks. Eligible candidates for enrolment in Swiss-AF were obtained by comprehensive screening of in- and outpatients in participating hospitals and by contacting general practitioners. The study complies with the Declaration of Helsinki. 
The local ethics committees approved the study protocol and written informed consent was obtained from all participants. All study sites received the approval of their cantonal ethical committee. The ethical committees involved were the following: Northwest and central Switzerland, Bern, Geneva, Vaud, Saint Gall, Ticino and Zurich.

Non-fasting venous blood samples were collected from each patient at baseline and stored at $-80^{\circ} \mathrm{C}$. Participants gave their consent for the storage of their blood samples in the biobank as well as the use for further projects. For the current project, thyroid function measurement was performed in all participants with available blood samples (97\%). Electrochemiluminescence immunoassays for TSH and fT4 were performed using the Elecsys detection method (cobas Elecsys, Roche Diagnostics GmbH, Mannheim, Germany). Thyroid function was defined as follows: overt hyperthyroidism ( $\mathrm{TSH}<0.45 \mathrm{mIU} / \mathrm{L}$ with elevated fT4), subclinical hyperthyroidism ( $\mathrm{TSH}<0.45 \mathrm{mIU} / \mathrm{L}$ with $\mathrm{fT} 4$ within the reference range), subclinical hypothyroidism (TSH 4.51-19.99 mIU/L with fT4 level within the reference range), overt hypothyroidism $(\mathrm{TSH} \geq 20.00 \mathrm{mIU} / \mathrm{L}$ or $\mathrm{TSH}>4.50 \mathrm{mIU} / \mathrm{L}$ with $\mathrm{fT} 4$ level below the reference range) and euthyroidism (TSH 0.45-4.50 mIU/L with fT4 within the reference range) (30).

\section{Patient and Public Involvement statement}

Patients and/or the public were not involved in the design, conduct, reporting or dissemination plans of this research.

\section{Outcomes and Covariates}

The primary outcome was a composite endpoint of CV events (myocardial infarctions (MIs), stroke/transitory ischemic events (TIAs), systemic embolism, hospitalizations for or HF and $\mathrm{CV}$ deaths). If a clinical outcome measure is reported by the patient or detected in the medical records, detailed information is collected from the corresponding hospitals and/or treating physicians about this event. The clinical events were adjudicated by a blinded event committee, which was not aware of thyroid function (28). Secondary outcomes were the 
components of the composite endpoint, total mortality and AF-progression. AF-progression was defined as 1) AF-progression from paroxysmal AF at baseline to non-paroxysmal AF (persistent or permanent AF) at the latest follow-up or as AF-progression from persistent AF at baseline to permanent $\mathrm{AF}$ at the latest follow-up (persistent if ECG during follow-up showed AF and did not show AF in previous study visits, permanent AF if a decision by the patient and physician not to pursue a rhythm control strategy was made) (clinical AFprogression) or 2) the need for rhythm control intervention (RCI) [antiarrhythmic intervention (either electro conversion (ECV) and/or pulmonary vein isolation (PVI) and/or start with amiodarone)] (18).

\section{Statistical Analysis}

Baseline characteristics were described separately for euthyroid participants, subclinical hypothyroid and subclinical hyperthyroid participants and also according to fT4 quintiles.

For the primary outcome we described the rates of $\mathrm{CV}$ outcomes in the above mentioned patient groups and examined the overall association of subclinical thyroid dysfunction and $\mathrm{CV}$ outcomes using Cox proportional-hazards models. We analyzed the associations separately for the following subgroups: euthyroid participants, subclinical hypothyroid and subclinical hyperthyroid participants and then with TSH as a continuous variable (within normal fT4) and as TSH quintiles. Secondary outcomes of the association of thyroid dysfunction with AF-progression were also analyzed using Cox proportional-hazards models. The same analyses were used for fT4 as continuous and fT4 quintiles as an exposure in the euthyroid individuals (each quintile represents $20 \%$ of the population with the middle quintile representing most of the population). We have checked the proportionality of the hazards function and it was fulfilled (8). There was no evidence against linearity using cubic splines regression (31). 
All the analyses were first adjusted for age and sex and in a following step, additional adjustment were done for smoking and body mass index (BMI), as these potential confounders may have an influence on thyroid function and the outcomes. Further, we performed post-hoc covariate adjustment for baseline imbalances: diabetes, previous CV disease, previous $\mathrm{HF}$, previous ECV, use of amiodarone, use of thyroid hormones, and hypothyroidism (32). We conducted subgroup analyses excluding patients taking thyroid hormone replacement and/or antithyroid medications at baseline. We also performed sensitivity analyses excluding patients who started "new" thyroid hormone replacement and/or antithyroid medications during follow-up. Since amiodarone could lead to changes in thyroid function, we performed sensitivity analyses excluding patients taking amiodarone at baseline. Most of the covariates -apart from age and BMI- were self-reported and there were very few values missing (See Table 1 footnotes). We also performed stratified analyses in subclinical hypothyroidism categories based on TSH: TSH 4.51-6.99 mIU/L and TSH 7.00$19.99 \mathrm{mIU} / \mathrm{L}(2)$.

Even though also adjudicated, since TIAs constitute a clinical diagnosis, we performed sensitivity analyses excluding TIAs from the composite outcome. Further, we performed sensitivity analyses taking center into account by using mixed-effects Cox regression models. For the primary endpoint we performed sensitivity analyses using competing risk regression for mortality, using Fine-Gray subdistribution hazard models (33). The method yields sub hazard ratios (SHR) with corresponding 95\% CI.

Our study had $>80 \%$ power to detect HR of 1.25 for the composite endpoint for subclinical hypothyroidism versus euthyroid persons. Regarding subclinical hyperthyroidism, our study had less power, specifically our study had $>80 \%$ power to detect a HR of 1.65 for subclinical hyperthyroidism for the composite endpoint. 
Statistical analyses were performed with STATA version 16.0 (StataCorp, College Station,TX) and R-Studio version 12.0, and a 2-sided a of 0.05 was considered to indicate statistical significance.

Results

\section{Baseline characteristics}

Of 2415 patients included in Swiss-AF cohort (mean age 73.2 years; 27\% women; 315 patients $(13 \%)$ of the total population under 65 years), TSH and fT4 measurement was complete in 2332 (97\%) patients, which were included in the present analyses. Baseline characteristics of patients with (97\%) and without blood samples (3\%) did not show any meaningful differences (Table 1). Data on potentially eligible patients denying participation have not been systematically collected in all study centers. In the study centre of Bern (2nd largest study site), data on adults declining participation were collected over the full recruitment period of 39 months, and around $64 \%$ of possible eligible participants denied participation due to "study design related issues ("too complicated")", "lack of interest for participation in studies" or "age or health related issues".

$26(1.1 \%)$ participants were lost to follow up $(n=20$ euthyroid participants, $n=4$ with subclinical hypothyroidism, $\mathrm{n}=1$ with clinical hyperthyroidism, $\mathrm{n}=1$ with clinical hypothyroidism). On baseline, 608 (26.1\%) had a history of HF and $789(33.6 \%)$ had a history of CV disease (Table 1). Comorbid conditions included hypertension $(69.9 \%)$ and diabetes mellitus (17.4\%). 1144 (49.1\%) were taking statins at baseline, 407 (17.5\%) were taking amiodarone and 229 (9.8\%) were taking thyroid hormones. Median TSH level was 2.0 $\mathrm{mIU} / \mathrm{L}$, median fT4 level was $16.0 \mathrm{pmol} / \mathrm{L}$. Overall, $86.3 \%$ were euthyroid, $8.4 \%$ had subclinical hypothyroidism, 2.3\% had subclinical hyperthyroidism, 1.5\% had overt hyperthyroidism and $1.4 \%$ had overt hypothyroidism. 11 patients could not be classified on a thyroid function category because of incompatible TSH and fT4 values. 


\section{Subclinical thyroid function and CV events}

Over a median 2.1 years of follow-up (maximal 5 years), 394 composite endpoint events occurred. There were 65 Strokes and 23 TIAs, 6 systemic embolism events, 49 MIs, 129 cardiac deaths and $227 \mathrm{HF}$ events. After adjusting for age and sex, neither subclinical hypothyroidism (HR 0.99 95\%CI 0.69-1.41) nor subclinical hyperthyroidism (HR 0.55 95\%CI 0.23-1.32) were associated with increased risk of the composite endpoint or the individual outcomes compared with euthyroidism (Table 2). For subclinical hypothyroidism with a TSH level of 7.00 to $19.99 \mathrm{mIU} / \mathrm{L}$, there was a no statistically significant association with the composite endpoint (HR 1.27 95\%CI 0.76-2.13) (Table 2). Similar results were obtained in all models after adjusting for smoking and BMI as well as after adjusting for baseline imbalances: previous diabetes, previous CV disease, previous HF, previous ECV, baseline use of amiodarone, baseline use of thyroid hormones, and previous hypothyroidism (Appendix Table 1a). Results remained the same in stratified analyses according to baseline CV disease ( $\mathrm{p}$ for interaction $>0.05$ ) (Appendix Table $1 \mathrm{~b}$ ).

TSH as a continuous variable (within normal fT4 levels) was not associated with CV events and the composite endpoint (Appendix Table 2). Sensitivity analyses with log transformation of TSH, to account for a not normal distribution, did not materially changed our results. Results remained similar in sensitivity analyses excluding patients with baseline thyroid altering medications $(\mathrm{n}=247)$ (Appendix Table 3), as well as excluding patients who initiated thyroid hormones during follow-up ( $\mathrm{n}=56)$ (currently not shown) and after taking TSHquintiles as an exposure (currently not shown). Similar results were obtained using competing risk models accounting for all-cause death as a competing event (Appendix Table 4) and after excluding TIAs from the composite endpoint (currently not shown). 


\section{FT4 in euthyroid participants}

FT4 as a continuous variable among euthyroid participants was associated with the composite endpoint, HF events and CV death as well as overall mortality (Figure 1a, Appendix Table 5). Results remained significant for the composite endpoint and HF events after adjusting for age, sex, BMI and smoking as well as after excluding participants with baseline amiodarone or thyroid altering medications (Figure 1b, 1c, Appendix Table 5). Our results remained robust following sensitivity analyses after log transformation of fT4 levels.

Appendix Table 6 describes baseline characteristics according to fT4 quintiles. Euthyroid participants in the highest fT4 quintile compared with the middle quintile of fT4 levels showed a higher risk of the composite outcome (age- and sex-adjusted HR 1.46 95\%CI 1.042.05) and HF events (age- and sex-adjusted HR 1.70 95\%CI 1.08-2.66) (Table 3). Since participants in the highest quintile were considerably more often taking amiodarone at baseline (Appendix Table 6) we performed sensitivity analyses excluding patients under amiodarone and the results remained similar (Appendix Table 7). Participants in the highest quintile had more commonly history of HF at baseline, previous CV disease as well previous ECV (Appendix Table 6). Results did not change after taking these factors in the multivariable model (Appendix Table 8). A quarter of patients within the highest quintile of fT4 levels were on thyroid hormone supplementation (Appendix Table 6). After excluding patients with thyroid altering medications at baseline $(n=157)$ as well as patients starting thyroid hormones during follow-up $(\mathrm{n}=18)$, results remained significant only for HF events (age- and sex-adjusted HR 1.83 95\% CI 1.12-2.98). After excluding patients on thyroid altering medications, a significant association for the composite endpoint remained when fT4 was analysed as a continuous outcome (HR $1.1695 \%$ CI 1.10-1.28) per 5 Units increase in fT4), the same association was not significant when fT4 was analysed in quintiles (HR 1.36 95\% CI 0.94-1.97) for the highest quintile vs middle quantile) (Appendix Table 9). Results 
remained significant for the composite endpoint and HF events after performing competing risks models accounting for all-cause death as a competing event (Appendix Table 10) and after excluding TIAs from the composite endpoint (currently not shown). Sensitivity analyses taking study center into account using mixed-effects Cox regression models did not materially change our results.

\section{AF-progression}

Clinical AF-progression occurred in 290 patients, while 234 patients had a rhythm control intervention. Neither subclinical hypothyroidism (age and sex-adjusted HR 1.05 95\%CI 0.691.60) nor subclinical hyperthyroidism (age and sex-adjusted HR $1.0895 \%$ CI $0.53-2.18$ ) were associated with increased risk of clinical AF-progression (Appendix Table 11). Similar results were obtained for pharmacological progression (Table 3). Results remained similar after additional adjustment for smoking and BMI (currently not shown). We also performed analyses using fT4 quintiles as an exposure with AF-progression as an outcome, and we found no association (currently not shown).

\section{Discussion}

In this large prospective cohort, we investigated the association of subclinical thyroid dysfunction with $\mathrm{CV}$ events in patients with established AF. Subclinical thyroid dysfunction was not associated with CV events, mortality or AF-progression. However, higher levels of fT4 alone at baseline were associated with higher risk for HF hospitalizations.

The association between thyroid dysfunction- both overt and subclinical- with new onset AF is well established and thyroid function tests are recommended in all patients with new onset of $\operatorname{AF}(7,9,11,34,35)$. However, the clinical and predictive significance of subclinical thyroid dysfunction in patients with established AF has not been previously investigated. A number of prospective cohort studies and individual participant meta-analyses in the general population have shown that there may be an association of both subclinical hypo- or 
hyperthyroidism with increased CV events, particularly for extreme TSH values, but results remain conflicting (34) (36). These associations may be particularly important in patients with established AF, which are substantially different in comparison to the general population in terms of comorbidities and treatments (37). Furthermore, thyroid hormones may increase the sympathetic tone, alter ionic channels or decrease atrial refractory periods (37), while both subclinical hypothyroidism and hyperthyroidism may contribute to a hypercoagulable state $(37,38)$, effects which may be important in patients with established AF in respect of AFprogression or development of CV events (37). Previous small studies have suggested that hyperthyroidism may represent an independent risk factor for stroke in patients with AF and thus further contributing to the already increased risk (24), while this was not verified in larger populations $(23,25)$. In accordance with that, we did not find an increased risk for stroke or other CV events in patients with AF and subclinical hyperthyroidism. Nevertheless, our study may have been underpowered to detect these differences. According to our results the effect of subclinical hyperthyroidism on the composite endpoint had a range of 0.23 to $1.32(95 \% \mathrm{CI})$. In the present study, we did not find any significant association between subclinical hypothyroidism and CV events, although a pattern of an association for higher TSH values could be discerned, which is consistent with other previous studies $(2,4,5)$. For this subgroup, our study had fewer patients, which might explain the lack of statistical significance. Lastly, we examined if subclinical thyroid dysfunction was associated with AFprogression, but did not find any significant association.

Our results showed an association between higher fT4 and CV and HF hospitalization events in euthyroid participants with established AF. Results for HF hospitalizations, a particularly important outcome in the AF population (39), remained significant in sensitivity analyses excluding participants with substituted hypothyroidism or amiodarone treatment. The association with fT4 levels with CV events and mortality has been described in other studies 
in the general population $(8,16,40,41)$. A prospective study in a cohort of 2843 communitydwelling euthyroid individuals of $>65$ years old has also examined the association of fT 4 and HF events and have also shown an association between higher fT4 and HF events (HR 1.05, 95\% CI 1.02-1.09), while no association between TSH was detected (16). These results are consistent with the known physiological end-organ effect of free thyroid hormones on heart rate and pump function (37). As there is a loglinear relationship between TSH and fT4, it would be expected that thyroid function would be best represented by TSH levels. However we did not find this constellation. A possible explanation could be that in the older population pituitary reaction could be delayed and thus they could have a higher TSH norm than the young healthier population, as previously postulated (16). Our results may point the fact that fT4 measurement may be a more precise tool to predict HF events but additional research is needed to clarify if this association is causal and if so, through which mechanisms. In this direction, one recent Mendelian randomization study has assessed the association between fT4 and HF (34). Using data from the UK biobank, this study did not find a significant causal effect of thyroid function on HF in the general population (34). However, a limitation of this study was the low power in the analysis of HF as an outcome and more similar studies are needed. This is of particular clinical importance and should be further investigated in the AF population, since they already have an increased risk for HF (39).

A quarter of patients within the highest quintile of fT4 levels among euthyroid individuals were on thyroid hormone supplementation. After excluding these subjects from the analyses, results remained significant for $\mathrm{HF}$ events but not for the composite $\mathrm{CV}$ events. This may be due to lower power of analyses in quintiles, or this could indirectly suggest that higher risk of composite $\mathrm{CV}$ events may be associated with an oversubstitution of previous (subclinical) hypothyroidism in patients with AF. More studies are needed to assess the effect of fT4 levels due to subclinical hypothyroidism treatment on CV events in such patients. This is crucial 
considering common oversubstitution and overtreatment of subclinical hypothyroidism in patients with known cardiac co-morbidities (42).

Among the strengths of our study, this is the first prospective cohort investigating subclinical thyroid dysfunction in the AF population. The prospective nature with careful design and collection of data increases the internal validity. In addition, we performed sensitivity analyses addressing many of the shortcomings of other studies in this field including thorough assessment of the impact of amiodarone treatment, potential competing risk of death, and a number of important subgroup analysis (33). Furthermore, the primary outcome was adjudicated through an independent committee.

Among the limitations of our study, TSH and fT4 were assessed only once at baseline and therefore we could not assess how many patients with subclinical dysfunction progressed to overt dysfunction or if the results were due to interactions with the assay. We reduced this limitation by performing sensitivity analyses excluding patients starting new thyroid treatment during follow-up. Furthermore, interindividual variability would be expected to attenuate rather than enhance underlying associations, as previously described (40). Second, fT3 was not measured. This is important for patients with subclinical hyperthyroidism since it may lead to a misclassification and thus underestimate the numbers of patients with overt hyperthyroidism. Nevertheless, this would be an issue in case in which an association between subclinical hyperthyroidism and adverse outcomes was found. A low fT3 level could be a reflection of a non-thyroidal illness, nevertheless, participants with any acute illness in the last 4 weeks were excluded as per protocol and recruited only following recovering thus making non-thyroidal illness less possible. Third, in our study the female population represented a minority $(27.2 \%)$, which is compatible with more male patients suffering from AF and therefore reflects an AF population (43). By nature of our cohort we cannot rule out a possible selection bias. Data collection on adults declining participation from one study site (Bern, 2nd 
largest study site) indicated a possible selection bias due to non-participation and thus a possible healthy volunteer effect, unfortunately these data have not been collected in other study centers. Fourth, although our study is the first to investigate the association of subclinical thyroid dysfunction with AF-progression, this outcome was not adjudicated, and we did not have continuous ECG monitoring. Fifth, a considerable proportion of our participants was treated with amiodarone, a common treatment in patients with AF, which could have affected the thyroid function tests. Nevertheless, after excluding participants on amiodarone treatment in sensitivity analyses the association between fT4 and CV events was robust. In addition, data have suggested that amiodarone induced thyrotoxicosis with higher fT4 levels compared to lower fT4 may be associated with an increased CV risk (44). Sixth, our study had less power to detect meaningful differences between subclinical hyperthyroidism and CV events (80\% power to detect a HR of 1.65$)$. Finally, the data are observational and the possibility of residual confounding cannot be excluded.

\section{Conclusion}

The analysis of this population-based prospective study showed that elderly patients with established AF and subclinical hypothyroidism did not have an increased risk of CV events. Subclinical hyperthyroidism was also not associated with CV events, even though our study had a lower power to detect these associations ( $80 \%$ power to detect a HR of 1.65$)$.Higher levels of fT4 in euthyroid patients at baseline were associated with higher risk for HF hospitalizations.

\section{Acknowledgements and affiliations}

The authors thank all the participants from the Swiss-AF cohort: the patients, the medical staff, nurses, laboratories and secretarial staff. The author also thank all the co-authors for the collaboration. 


\section{Authors' Contributions}

Elisavet Moutzouri wrote the first version of the manuscript with support of Christina Lyko. Elisavet Moutzouri performed statistical analyses. Martin Feller, Manuel Blum, Cinzia Del Giovane verified statistical analyses and interpreted the results.

Nicolas Rodondi, David Conen, Martin Feller, Luise Adam conceived and developed the project idea.

Steffen Blum, Stefanie Aeschbacher contributed to the analytical methods.

Fischer Urs, Roten Laurent, Christine Stefanie Meyer-Zuern, Giulio Conte, Leo H. Bonati, Giorgio Moschovitis, Michael Kühne, Juerg Hans Beer, Drahomir Antonin Aujesky, Stefan Osswald contributed to the design of the study and patient recruitment as well as critical interpretation of the results

Nicolas Rodondi supervised the project.

All authors contributed to the final version of the manuscript.

\section{Measurements and abbreviations}

AF atrial fibrillation

adjHR adjusted hazard ratio

BMI body mass index

CHD coronary heart disease

CI confidence interval

CV cardiovascular

ECG electrocardiogramm

ECV electro conversion

fT4 free thyroxine

HF heart failure 
HR hazard ratio

MI myocardial infarction

PVI pulmonary vein isolation

RCI rhythm control intervention

SHR sub hazard ratios

TIA transitory ischemic event

TSH thyroid-stimulating hormone

\section{Disclosure}

\section{Funding}

The Swiss-AF cohort study is supported by grants of the Swiss National Science Foundation (Grant numbers 33CS30_148474 and 33CS30_177520). The work of Elisavet Moutzouri and Christina Lyko is funded by a grant from the Swiss National Science foundation (SNSF 320030-172676 to Nicolas Rodondi). David Conen holds a McMaster University Department of Medicine Mid-Career Research Award. TSH and fT4 measurements were provided free of charge from Roche.

\section{Conflict of interest}

Dr. Beer reports grants from the Swiss National Foundation of Science and the Swiss Heart Foundation. Dr. Kühne reports personal fees from Bayer, personal fees from Böhringer Ingelheim, personal fees from Pfizer BMS, personal fees from Daiichi Sankyo, personal fees from Medtronic, personal fees from Biotronik, personal fees from Boston Scientific, personal fees from Johnson\&Johnson, grants from Bayer, grants from Pfizer BMS, grants from Boston Scientific, grants from Swiss National Science Foundation, grants from Swiss Heart Foundation. Dr. Bonati has received an unrestricted research grant from AstraZeneca, as well as consultancy and advisory board fees from Amgen, Bayer, Bristol-Myers Squibb, and Claret 
Medical. Dr. Conen received speaker fees from Servier, Canada, outside of the current work.

Dr Fischer is a consultant for Medtronic, Stryker and CSL Behring and Co-PI of the SWIFT

DIRECT trial und the BEYOND SWIFT registry (Medtronic). Dr. Moschovitis reports fees

for participating to advisory boards from AstraZeneca and Novartis outside of this project. Dr.

Roten reports speaker/consulting honoraria from Abbott and Medtronic.

\section{References}

1. Kim YA, Park YJ. Prevalence and risk factors of subclinical thyroid disease. Endocrinology and metabolism. 2014;29(1):20-9.

2. Rodondi N, den Elzen WP, Bauer DC, Cappola AR, Razvi S, Walsh JP, Asvold BO, lervasi G, Imaizumi M, Collet TH, et al. Subclinical hypothyroidism and the risk of coronary heart disease and mortality. Jama. 2010;304(12):1365-74.

3. Collet TH, Gussekloo J, Bauer DC, den Elzen WP, Cappola AR, Balmer P, lervasi G, Asvold BO, Sgarbi JA, Volzke $H$, et al. Subclinical hyperthyroidism and the risk of coronary heart disease and mortality. Archives of internal medicine. 2012;172(10):799-809.

4. Gencer B, Collet TH, Virgini V, Bauer DC, Gussekloo J, Cappola AR, Nanchen D, den Elzen WP, Balmer $P$, Luben RN, et al. Subclinical thyroid dysfunction and the risk of heart failure events: an individual participant data analysis from 6 prospective cohorts. Circulation. 2012;126(9):1040-9.

5. Nanchen D, Gussekloo J, Westendorp RG, Stott DJ, Jukema JW, Trompet S, Ford I, Welsh P, Sattar N, Macfarlane PW, et al. Subclinical thyroid dysfunction and the risk of heart failure in older persons at high cardiovascular risk. J Clin Endocrinol Metab. 2012;97(3):852-61.

6. Chaker L, Baumgartner C, den Elzen WP, Ikram MA, Blum MR, Collet TH, Bakker SJ, Dehghan A, Drechsler C, Luben RN, et al. Subclinical Hypothyroidism and the Risk of Stroke Events and Fatal Stroke: An Individual Participant Data Analysis. J Clin Endocrinol Metab. 2015;100(6):2181-91.

7. Selmer C, Olesen JB, Hansen ML, Lindhardsen J, Olsen AM, Madsen JC, Faber J, Hansen PR, Pedersen OD, Torp-Pedersen $C$, et al. The spectrum of thyroid disease and risk of new onset atrial fibrillation: a large population cohort study. Bmj. 2012;345:e7895.

8. Baumgartner C, da Costa BR, Collet TH, Feller M, Floriani C, Bauer DC, Cappola AR, Heckbert SR, Ceresini G, Gussekloo J, et al. Thyroid Function Within the Normal Range, Subclinical Hypothyroidism, and the Risk of Atrial Fibrillation. Circulation. 2017;136(22):2100-16.

9. Camm AJ, Lip GY, De Caterina R, Savelieva I, Atar D, Hohnloser SH, Hindricks G, Kirchhof P, Guidelines ESCCFP. 2012 focused update of the ESC Guidelines for the management of atrial fibrillation: an update of the 2010 ESC Guidelines for the management of atrial fibrillation. Developed with the special contribution of the European Heart Rhythm Association. European heart journal. 2012;33(21):2719-47.

10. European Heart Rhythm A, European Association for Cardio-Thoracic S, Camm AJ, Kirchhof P, Lip GY, Schotten U, Savelieva I, Ernst S, Van Gelder IC, Al-Attar N, et al. Guidelines for the management of atrial fibrillation: the Task Force for the Management of Atrial Fibrillation of the European Society of Cardiology (ESC). European heart journal. 2010;31(19):2369-429.

11. Cappola AR, Fried LP, Arnold AM, Danese MD, Kuller LH, Burke GL, Tracy RP, Ladenson PW. Thyroid status, cardiovascular risk, and mortality in older adults. Jama. 2006;295(9):1033-41.

12. Woeber KA. Thyrotoxicosis and cardiac disease. Heart Dis Stroke. 1993;2(5):415-7. 
13. Norberg J, Backstrom S, Jansson JH, Johansson L. Estimating the prevalence of atrial fibrillation in a general population using validated electronic health data. Clinical epidemiology. 2013;5:475-81.

14. Auer J, Scheibner P, Mische T, Langsteger W, Eber O, Eber B. Subclinical hyperthyroidism as a risk factor for atrial fibrillation. American heart journal. 2001;142(5):838-42.

15. Mammen JS, McGready J, Oxman R, Chia CW, Ladenson PW, Simonsick EM. Thyroid Hormone Therapy and Risk of Thyrotoxicosis in Community-Resident Older Adults: Findings from the Baltimore Longitudinal Study of Aging. Thyroid : official journal of the American Thyroid Association.

2015;25(9):979-86.

16. Cappola AR, Arnold AM, Wulczyn K, Carlson M, Robbins J, Psaty BM. Thyroid function in the euthyroid range and adverse outcomes in older adults. J Clin Endocrinol Metab. 2015;100(3):108896.

17. Kirchhof P, Benussi S, Kotecha D, Ahlsson A, Atar D, Casadei B, Castella M, Diener HC, Heidbuchel $\mathrm{H}$, Hendriks J, et al. 2016 ESC Guidelines for the management of atrial fibrillation developed in collaboration with EACTS. European heart journal. 2016;37(38):2893-962.

18. Blum S, Aeschbacher S, Meyre P, Zwimpfer L, Reichlin T, Beer JH, Ammann P, Auricchio A, Kobza R, Erne P, et al. Incidence and Predictors of Atrial Fibrillation Progression. Journal of the American Heart Association. 2019;8(20):e012554.

19. Steinberg BA, Hellkamp AS, Lokhnygina Y, Patel MR, Breithardt G, Hankey GJ, Becker RC, Singer DE, Halperin JL, Hacke W, et al. Higher risk of death and stroke in patients with persistent vs. paroxysmal atrial fibrillation: results from the ROCKET-AF Trial. European heart journal. 2015;36(5):288-96.

20. Ntaios G, Vemmou A, Koroboki E, Savvari P, Makaritsis K, Saliaris M, Andrikopoulos G, Vemmos $\mathrm{K}$. The type of atrial fibrillation is associated with long-term outcome in patients with acute ischemic stroke. International journal of cardiology. 2013;167(4):1519-23.

21. de Vos CB, Pisters R, Nieuwlaat R, Prins MH, Tieleman RG, Coelen RJ, van den Heijkant AC, Allessie MA, Crijns HJ. Progression from paroxysmal to persistent atrial fibrillation clinical correlates and prognosis. Journal of the American College of Cardiology. 2010;55(8):725-31.

22. Poulin MF, Doukky R. Hyperthyroid atrial fibrillation: does it matter for stroke risk? Cardiology. 2014;128(1):51-3.

23. Bruere H, Fauchier L, Bernard Brunet A, Pierre B, Simeon E, Babuty D, Clementy N. History of thyroid disorders in relation to clinical outcomes in atrial fibrillation. The American journal of medicine. 2015;128(1):30-7.

24. Chen Q, Yan Y, Zhang L, Cheng K, Liu Y, Zhu W. Effect of hyperthyroidism on the hypercoagulable state and thromboembolic events in patients with atrial fibrillation. Cardiology. 2014;127(3):176-82.

25. Friberg L, Rosenqvist M, Lip GY. Evaluation of risk stratification schemes for ischaemic stroke and bleeding in 182678 patients with atrial fibrillation: the Swedish Atrial Fibrillation cohort study. European heart journal. 2012;33(12):1500-10.

26. Vergara P, Picardi G, Nigro G, Scafuro F, de Chiara A, Calabro R, Vergara G. Evaluation of thyroid dysfunction in patients with paroxysmal atrial fibrillation. Anadolu kardiyoloji dergisi : AKD = the Anatolian journal of cardiology. 2007;7 Suppl 1:104-6.

27. Massicotte-Azarniouch D, Kuwornu JP, Carrero JJ, Lam NN, Molnar AO, Zimmerman D, McCallum MK, Garg AX, Sood MM. Incident Atrial Fibrillation and the Risk of Congestive Heart Failure, Myocardial Infarction, End-Stage Kidney Disease, and Mortality Among Patients With a Decreased Estimated GFR. American journal of kidney diseases : the official journal of the National Kidney Foundation. 2018;71(2):191-9.

28. Conen D, Rodondi N, Mueller A, Beer J, Auricchio A, Ammann P, Hayoz D, Kobza R, Moschovitis G, Shah D, et al. Design of the Swiss Atrial Fibrillation Cohort Study (Swiss-AF): structural brain damage and cognitive decline among patients with atrial fibrillation. Swiss medical weekly. 2017;147:w14467. 
29. Conen D, Rodondi N, Muller A, Beer JH, Ammann P, Moschovitis G, Auricchio A, Hayoz D, Kobza R, Shah D, et al. Relationships of Overt and Silent Brain Lesions With Cognitive Function in Patients With Atrial Fibrillation. Journal of the American College of Cardiology. 2019;73(9):989-99. 30. Blum MR, Bauer DC, Collet TH, Fink HA, Cappola AR, da Costa BR, Wirth CD, Peeters RP, Asvold $\mathrm{BO}$, den Elzen WP, et al. Subclinical thyroid dysfunction and fracture risk: a meta-analysis. Jama. 2015;313(20):2055-65.

31. P. Royston WSMm-bapatrabofpfmcrW, Chichester, UK (2008).

32. Christensen $\mathrm{R}$, Langberg $\mathrm{H}$. Statistical principles for prospective study protocols:: design, analysis, and reporting. International journal of sports physical therapy. 2012;7(5):504-11.

33. Abdel-Qadir H, Fang J, Lee DS, Tu JV, Amir E, Austin PC, Anderson GM. Importance of Considering Competing Risks in Time-to-Event Analyses: Application to Stroke Risk in a Retrospective Cohort Study of Elderly Patients With Atrial Fibrillation. Circulation Cardiovascular quality and outcomes. 2018;11(7):e004580.

34. Larsson SC, Allara E, Mason AM, Michaelsson K, Burgess S. Thyroid Function and Dysfunction in Relation to 16 Cardiovascular Diseases. Circulation Genomic and precision medicine. 2019;12(3):e002468.

35. Ellervik C, Roselli C, Christophersen IE, Alonso A, Pietzner M, Sitlani CM, Trompet S, Arking DE, Geelhoed B, Guo X, et al. Assessment of the Relationship Between Genetic Determinants of Thyroid Function and Atrial Fibrillation: A Mendelian Randomization Study. JAMA cardiology. 2019;4(2):144-52.

36. Gencer B, Collet TH, Virgini V, Auer R, Rodondi N. Subclinical thyroid dysfunction and cardiovascular outcomes among prospective cohort studies. Endocrine, metabolic \& immune disorders drug targets. 2013;13(1):4-12.

37. Floriani C, Gencer B, Collet TH, Rodondi N. Subclinical thyroid dysfunction and cardiovascular diseases: 2016 update. European heart journal. 2018;39(7):503-7.

38. Elbers LPB, Fliers E, Cannegieter SC. The influence of thyroid function on the coagulation system and its clinical consequences. Journal of thrombosis and haemostasis : JTH. 2018;16(4):63445.

39. Chatterjee NA, Chae CU, Kim E, Moorthy MV, Conen D, Sandhu RK, Cook NR, Lee IM, Albert CM. Modifiable Risk Factors for Incident Heart Failure in Atrial Fibrillation. JACC Heart failure. 2017;5(8):552-60.

40. Yeap BB, Alfonso H, Hankey GJ, Flicker L, Golledge J, Norman PE, Chubb SA. Higher free thyroxine levels are associated with all-cause mortality in euthyroid older men: the Health In Men Study. European journal of endocrinology. 2013;169(4):401-8.

41. Waring AC, Arnold AM, Newman AB, Buzkova P, Hirsch C, Cappola AR. Longitudinal changes in thyroid function in the oldest old and survival: the cardiovascular health study all-stars study. J Clin Endocrinol Metab. 2012;97(11):3944-50.

42. Perros P, Nirantharakumar K, Hegedus L. Recent evidence sets therapeutic targets for levothyroxine-treated patients with primary hypothyroidism based on risk of death. European journal of endocrinology. 2020.

43. Chugh SS, Havmoeller R, Narayanan K, Singh D, Rienstra M, Benjamin EJ, Gillum RF, Kim YH, McAnulty JH, Jr., Zheng ZJ, et al. Worldwide epidemiology of atrial fibrillation: a Global Burden of Disease 2010 Study. Circulation. 2014;129(8):837-47.

44. Yiu KH, Jim MH, Siu CW, Lee CH, Yuen M, Mok M, Shea YF, Fan K, Tse HF, Chow WH. Amiodarone-induced thyrotoxicosis is a predictor of adverse cardiovascular outcome. J Clin Endocrinol Metab. 2009;94(1):109-14. 
Figure legends

Figure 1a. Age- and sex-adjusted CV events per 5 Units increase in fT4 in all euthyroid patients

Figure 1b. Age- and sex- adjusted CV events per 5 Units increase in fT4 excluding patients on amiodarone $(\mathrm{n}=308)$

Figure 1c. Age- and sex- adjusted CV events per 5 Units increase in fT4 excluding patients on thyroid altering medications $(\mathrm{n}=175)$

Abbreviations: CV: cardiovascular, HF: heart failure, HR: Hazard Ratio, MI: myocardial infarction, TIA: transient ischemic event 
Table 1. Baseline characteristics of included participants stratified by thyroid function. Data are presented as $n$ (\%), mean \pm S.D. or as median (IQR).

\begin{tabular}{|l|l|l|l|l|l|}
\hline Variables & $\begin{array}{l}\text { All } \\
\text { participants* }\end{array}$ & $\begin{array}{l}\text { Subclinical } \\
\text { Hyperthyroidism }\end{array}$ & Euthyroidism & $\begin{array}{l}\text { Subclinical } \\
\text { Hypothyroidism }\end{array}$ & $\begin{array}{l}\text { Participants without } \\
\text { blood samples }\end{array}$ \\
\hline$n(\%)$ & 2332 & $53(2.3)$ & $2004(86.3)$ & $196(8.4)$ & 83 \\
\hline Age, years & $73.3 \pm 8.4$ & $73.5 \pm 8.6$ & $73.2 \pm 8.5$ & $73.3 \pm 8.2$ & $72.5 \pm 8.8$ \\
\hline Female & $635(27.2)$ & $20(37.7)$ & $524(26.2)$ & $62(31.6)$ & $27(32.5)$ \\
\hline BMl, kg/m ${ }^{2}$ & $27.7 \pm 4.8$ & $27.9 \pm 4.5$ & $27.6 \pm 4.8$ & $27.8 \pm 5.1$ & $28.3 \pm 4.6$ \\
\hline Smoking ${ }^{a}$ & & & & & \\
\hline$\quad$ Never & $1020(43.8)$ & $30(56.6)$ & $869(43.4)$ & $91(46.4)$ & $38(45.8)$ \\
\hline$\quad$ Past & $1140(48.9)$ & $19(35.9)$ & $989(49.4)$ & $88(44.9)$ & $39(47.0)$ \\
\hline$\quad$ Current & $170(7.3)$ & $4(7.6)$ & $144(7.2)$ & $17(8.7)$ & $6(7.3)$ \\
\hline TSH mlU/L & $2.0(1.3-3.0)$ & $0.3(0.1-0.4)$ & $1.9(1.3-2.7)$ & $5.8(4.9-7.5)$ & - \\
\hline FT4 pmol/L & $16.0(14.4-18.3)$ & $17.5(15.9-19.3)$ & $16.0(14.4-18.2)$ & $15.4(14.1-17.3)$ & - \\
\hline Thyreostatic use & $19(0.8)$ & $5(9.4)$ & $6(0.3)$ & $4(2.0)$ & $2(2.4)$ \\
\hline Thyroid hormones use & $229(9.8)$ & $16(30.2)$ & $151(7.5)$ & $39(19.9)$ & $10(12.0)$ \\
\hline Hypertension & $1623(69.9)$ & $39(73.6)$ & $1387(69.2)$ & $136(69.4)$ & $59(71.1)$ \\
\hline Diabetes & $405(17.4)$ & $4(7.5)$ & $347(17.3)$ & $36(18.4)$ & $6(7.2)$ \\
\hline Hypothyroidism & $230(11.2)$ & $16(30.2)$ & $157(7.8)$ & $56(28.6)$ & $10(12.0)$ \\
\hline Hyperthyroidism & $89(3.8)$ & $8(15.9)$ & $59(2.9)$ & $13(6.6)$ & $6(7.2)$ \\
\hline Known cardiovascular disease $^{\mathrm{b}}$ & $789(33.6)$ & $10(18.9)$ & $674(33.6)$ & $70(35.7)$ & $32(38.6)$ \\
\hline Previous electro conversion & $830(35.6)$ & $20(37.7)$ & $689(34.4)$ & $82(41.8)$ & $31(37.3)$ \\
\hline History of heart failure ${ }^{\mathrm{c}}$ & $608(26.1)$ & $7(13.2)$ & $503(25.1)$ & $65(33.2)$ & $18(21.7)$ \\
\hline Baseline statin & $1144(49.1)$ & $28(52.8)$ & $982(49.0)$ & $93(47.5)$ & $45(54.2)$ \\
\hline Baseline amiodarone & $407(17.5)$ & $4(7.6)$ & $308(15.4)$ & $63(32.1)$ & $17(20.5)$ \\
\hline
\end{tabular}

*All participants with available blood samples; $n=79$ participants with clinical hypothyroidism or hyperthyroidism not depicted in the table; Abbreviations: BMI: body mass index

${ }^{a} \mathrm{n}=2$ missing, ${ }^{b}$ Cardiovascular disease defined as previous myocardial infarction, bypass, peripheral arterial disease, ${ }^{c} n=1$ missing 
Table 2. Cardiovascular events and all-cause mortality by subclinical thyroid status at baseline in all participants

\begin{tabular}{|c|c|c|c|c|c|c|c|c|c|}
\hline \multirow[t]{3}{*}{\begin{tabular}{|l|} 
Thyroid Status \\
\end{tabular}} & \multirow{3}{*}{\begin{tabular}{|l|}
$\begin{array}{l}\text { Euthyroidism } \\
\text { with TSH }\end{array}$ \\
$0.45-4.49 \mathrm{mIU} / \mathrm{L}$ \\
$(n=2004)$ \\
Events \\
\end{tabular}} & \multicolumn{8}{|c|}{ Subclinical Hyperthyroidism with TSH } \\
\hline & & \multicolumn{2}{|c|}{$<0.45 \mathrm{mIU} / \mathrm{L}(n=53)$} & \multicolumn{2}{|c|}{$4.5-19.9 \mathrm{mIU} / \mathrm{L}(n=196)$} & \multicolumn{2}{|c|}{$4.5-7 \mathrm{mIU} / \mathrm{L}(n=129)$} & \multicolumn{2}{|c|}{$7-19.9 \mathrm{mIU} / \mathrm{L}(n=67)$} \\
\hline & & Events & HR $(95 \% \mathrm{CI})^{*}$ & Events & HR $(95 \%$ CI)* & Events & HR $(95 \%$ CI)* & Events & HR $(95 \% \mathrm{CI})^{*}$ \\
\hline Composite endpoint & 338 & 5 & $0.55(0.23-1.32)$ & 33 & $0.99(0.69-1.41)$ & 18 & $0.84(0.52-1.35)$ & 15 & $1.27(0.76-2.13)$ \\
\hline Stroke/TIA & 79 & 1 & \begin{tabular}{|l|}
$0.46(0.06-3.33$ \\
\end{tabular} & 7 & $0.88(0.41-1.92)$ & 4 & $0.81(0.30-2.21)$ & 3 & $1.01(0.32-3.21)$ \\
\hline MI & 46 & 2 & \begin{tabular}{|l|}
$1.89(0.46-7.80)$ \\
\end{tabular} & 6 & $1.51(0.64-3.56)$ & 5 & $1.95(0.77-4.95)$ & 1 & $0.71(0.10-5.15)$ \\
\hline HF-events & 191 & 3 & \begin{tabular}{|l|}
$0.59(0.19-1.83)$ \\
\end{tabular} & 17 & $0.90(0.55-1.48)$ & 7 & \begin{tabular}{|l|l|}
$0.57(0.27-1.20)$ \\
\end{tabular} & 10 & $1.55(0.82-2.93)$ \\
\hline CV death & 112 & 1 & \begin{tabular}{|l|}
$0.36(0.05-2.55)$ \\
\end{tabular} & 11 & \begin{tabular}{|l|}
$1.06(0.57-1.96)$ \\
\end{tabular} & 7 & $1.07(0.50-2.30)$ & 4 & $1.03(0.38-2.80)$ \\
\hline Total Mortality & 164 & 2 & \begin{tabular}{|l}
$0.48(0.11-1.95)$ \\
\end{tabular} & 17 & $1.09(0.66-1.79)$ & 9 & $0.92(0.47-1.81)$ & 8 & $1.37(0.67-2.79)$ \\
\hline
\end{tabular}

BMI: body mass index, CV: cardiovascular, HF: heart failure, HR: Hazard Ratio, MI: myocardial infarction, TIA: transient ischemic event.

- $\quad$ Age/sex- adjusted 
Table 3. Cardiovascular events and all-cause mortality by fT4 in quintiles in euthyroid participants at baseline ( $n=2004)$.

\begin{tabular}{|c|c|c|c|c|c|c|c|c|c|c|}
\hline & \multicolumn{10}{|c|}{ FT4 Quintiles IQR } \\
\hline & \multicolumn{2}{|c|}{$12.0-13.5(n=383)$} & \multicolumn{2}{|c|}{$14.4-15.0(n=411)$} & \multicolumn{2}{|c|}{$15.7-16.3(n=413)$} & \multicolumn{2}{|c|}{$17.2-18.3(n=416)$} & \multicolumn{2}{|c|}{$19.7-22.8(n=381)$} \\
\hline & Events & $\mathrm{HR}(95 \% \mathrm{Cl}) *$ & Events & $\mathrm{HR}(95 \% \mathrm{Cl})^{*}$ & Events & HR $(95 \% \mathrm{Cl})^{*}$ & Events & $\mathrm{HR}(95 \% \mathrm{Cl})^{*}$ & Events & $\mathrm{HR}(95 \% \mathrm{Cl})^{*}$ \\
\hline Composite endpoint & 59 & $1.08(0.76-1.54)$ & 62 & $1.00(0.70-1.40)$ & 65 & 1.00 & 80 & $1.38(0.99-1.91)$ & 72 & $1.46(1.04-2.05)^{a}$ \\
\hline Stroke/TIA & 20 & $1.49(0.77-2.88)$ & 10 & $0.64(0.29-1.43)$ & 16 & 1.00 & 21 & $1.44(0.76-2.78)$ & 12 & $0.90(0.42-1.92)$ \\
\hline $\mathrm{MI}$ & 5 & 0.49 (0.17-1.39) & 8 & $0.70(0.29-1.72)$ & 11 & 1.00 & 9 & $0.72(0.29-1.76)$ & 8 & $0.85(0.34-2.10)$ \\
\hline HF-events & 27 & $0.92(0.56-1.53)$ & 39 & $1.19(0.76-1.90)$ & 34 & 1.00 & 45 & $1.47(0.94-2.29)$ & 46 & $1.70(1.08-2.66)^{\mathrm{a}}$ \\
\hline CV death & 18 & $1.02(0.54-1.92)$ & 23 & $1.17(0.65-2.11)$ & 21 & 1.00 & 28 & $1.51(0.86-2.82)$ & 22 & $1.54(0.84-2.81)$ \\
\hline Total mortality & 28 & $1.10(0.67-1.84)$ & 35 & $1.23(0.75-2.00)$ & 30 & 1.00 & 40 & $1.49(0.93-2.40)$ & 31 & $1.47(0.88-2.43)$ \\
\hline
\end{tabular}

BMI: body mass index, CV: cardiovascular, HF: heart failure, HR: Hazard Ratio, MI: myocardial infarction, TIA: transient ischemic event ${ }^{a} p<0.05$

*age/sex adjusted 


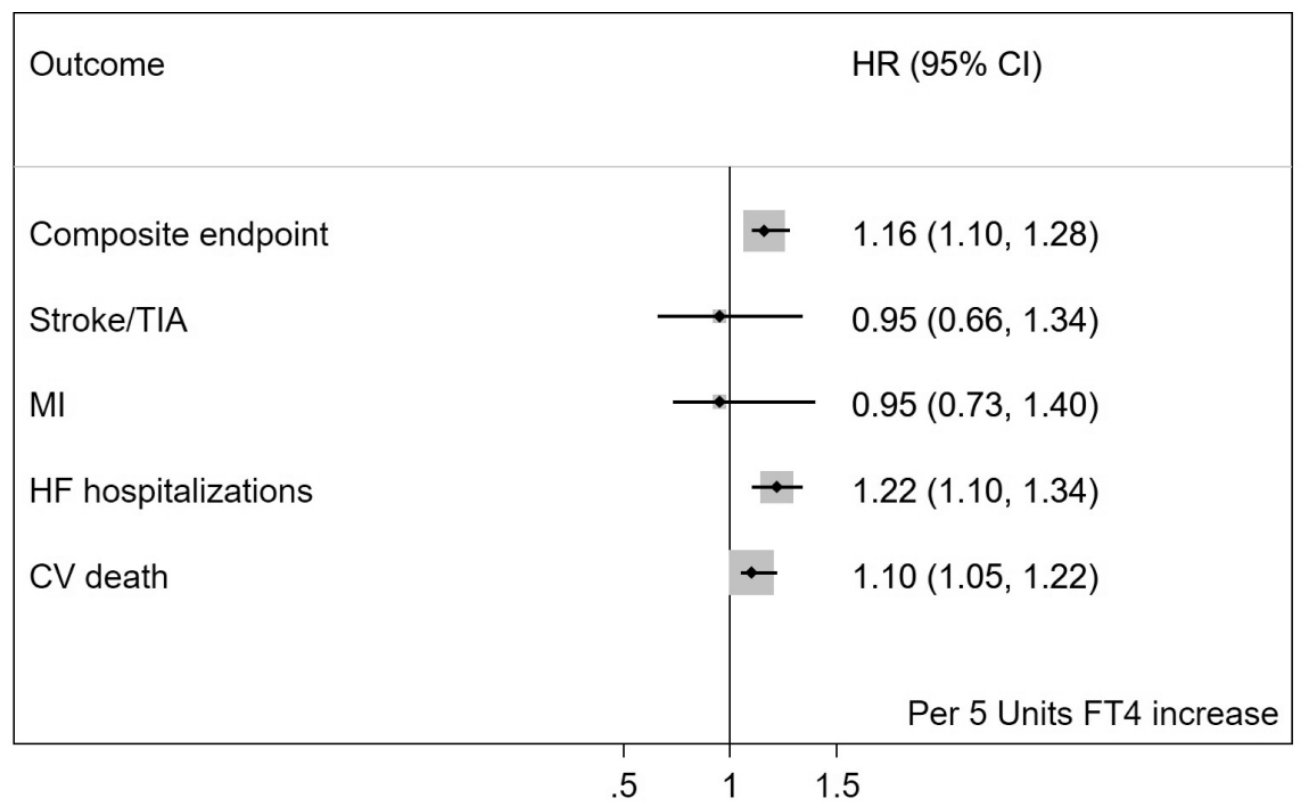

Figure 1a. Age- and sex- adjusted CV events per 5 Units increase in fT4 in all euthyroid patients $405 \times 257 \mathrm{~mm}(600 \times 600 \mathrm{DPI})$ 


\begin{tabular}{|c|c|c|}
\hline \multicolumn{2}{|l|}{ Outcome } & $\mathrm{HR}(95 \% \mathrm{Cl})$ \\
\hline Composite endpoint & $\leftarrow$ & $1.16(1.10,1.28)$ \\
\hline Stroke/TIA & $\longleftarrow$ & $1.05(0.86,1.28)$ \\
\hline MI & & $1.00(0.77,1.40)$ \\
\hline HF hospitalizations & $\rightarrow$ & $1.22(1.10,1.28)$ \\
\hline CV death & $\rightarrow$ & $1.10(0.95,1.22)$ \\
\hline & & Per 5 Units FT4 increase \\
\hline
\end{tabular}

Figure 1b. Age- and sex- adjusted CV events per 5 Units increase in fT4 excluding patients on amiodarone $(n=308)$

$404 \times 257 \mathrm{~mm}(600 \times 600 \mathrm{DPI})$ 


\begin{tabular}{|c|c|c|}
\hline \multicolumn{2}{|l|}{ Outcome } & $\mathrm{HR}(95 \% \mathrm{Cl})$ \\
\hline Composite endpoint & 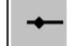 & $1.16(1.10,1.28)$ \\
\hline Stroke/TIA & 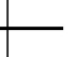 & $0.82(0.53,1.28)$ \\
\hline MI & & $0.95(0.62,1.54)$ \\
\hline HF hospitalizations & $\rightarrow$ & $1.22(1.10,1.28)$ \\
\hline CV death & $\rightarrow$ & $1.10(0.95,1.22)$ \\
\hline & & Per 5 Units FT4 increase \\
\hline & 1 & \\
\hline
\end{tabular}

Figure 1c. Age- and sex- adjusted CV events per 5 Units increase in fT4 excluding patients on thyroid altering medications $(n=175)$

$408 \times 257 \mathrm{~mm}(600 \times 600 \mathrm{DPI})$ 
Appendix Table 1a. Cardiovascular events and all-cause mortality by subclinical thyroid status at baseline in all participants (multivariable models) ( $\mathrm{N}=\mathbf{2 3 3 2}$ )

\begin{tabular}{|c|c|c|c|c|c|c|c|c|}
\hline & \multicolumn{2}{|c|}{$\begin{array}{l}\text { Subclinical Hyperthyroidism } \\
\text { with } \mathrm{TSH}<0.45 \mathrm{mIU} / \mathrm{L}\end{array}$} & \multicolumn{2}{|c|}{$\begin{array}{c}\text { Subclinical Hypothyroidism with } \\
\text { TSH } 4.5-19.9 \mathrm{mIU} / \mathrm{L}\end{array}$} & \multicolumn{2}{|c|}{$\begin{array}{c}\text { Subclinical Hypothyroidism with } \\
\text { TSH 4.5-7mIU/L }\end{array}$} & \multicolumn{2}{|c|}{$\begin{array}{c}\text { Subclinical Hypothyroidism with } \\
\text { TSH 7-19.9mIU/L }\end{array}$} \\
\hline & $\begin{array}{c}\mathrm{HR}(95 \% \mathrm{Cl}) \\
\text { multivariable } \\
\text { model }^{\mathrm{a}}\end{array}$ & $\begin{array}{c}\mathrm{HR}(95 \% \mathrm{Cl}) \\
\text { multivariable } \\
\text { model }^{\mathrm{b}}\end{array}$ & $\begin{array}{c}\mathrm{HR}(95 \% \mathrm{Cl}) \\
\text { multivariable } \\
\text { model }^{\mathrm{a}}\end{array}$ & $\begin{array}{l}\mathrm{HR}(95 \% \mathrm{Cl}) \\
\text { multivariable } \\
\text { model }^{\mathrm{b}}\end{array}$ & $\begin{array}{c}\mathrm{HR}(95 \% \mathrm{Cl}) \\
\text { multivariable } \\
\text { model }^{\mathrm{a}}\end{array}$ & $\begin{array}{c}\mathrm{HR}(95 \% \mathrm{Cl}) \\
\text { multivariable } \\
\text { model }^{\mathrm{b}}\end{array}$ & $\begin{array}{l}\mathrm{HR}(95 \% \mathrm{Cl}) \\
\text { multivariable } \\
\text { model }^{\mathrm{a}}\end{array}$ & $\begin{array}{l}\mathrm{HR}(95 \% \mathrm{Cl}) \\
\text { multivariable } \\
\text { model }^{\mathrm{b}}\end{array}$ \\
\hline Composite endpoint & 1.37) & $0.58(0.24-1.42)$ & $0.99(0.69-1.42)$ & $0.95(0.66-1.37)$ & $0.85(0.53-1.36)$ & $0.84(0.52-1.35)$ & $1.24(0.74-2.08)$ & $1.14(0.67-1.95)$ \\
\hline$M I$ & $\begin{array}{l}1.93(0.47- \\
8.04)\end{array}$ & $2.23(0.52-9.6)$ & $1.49(0.63-3.5)$ & $1.12(0.44-2.87)$ & $1.98(0.78-5.01)$ & $1.44(0.54-3.87)$ & $0.67(0.10-4.90)$ & $0.50(0.06-3.93)$ \\
\hline HF-events & $\begin{array}{c}0.62(0.19- \\
1.95)\end{array}$ & $0.75(0.24-2.39)$ & $0.90(0.55-1.47)$ & $0.88(0.53-1.46)$ & $0.57(0.27-1.21)$ & $0.58(0.27-1.24)$ & $1.50(0.79-2.84)$ & $1.40(0.72-2.72)$ \\
\hline CV death & $\begin{array}{l}0.42(0.06- \\
3.03)\end{array}$ & $0.36(0.05-2.58)$ & $1.06(0.57-1.97)$ & $0.91(0.48-1.73)$ & $1.08(0.50-2.32)$ & $0.95(0.43-2.06)$ & $1.03(0.38-2.80)$ & $0.88(0.31-2.45)$ \\
\hline
\end{tabular}

Abbreviations: BMI: body mass index, CV: cardiovascular, HF: heart failure, HR: Hazard Ratio, MI: myocardial infarction, TIA: transient ischemic event. The euthyroidism group was used as the reference group; For number of events see Table 2

${ }^{a}$ adjusted for age, sex, BMI, smoking status ${ }^{b}$ adjusted for: age, sex, BMI, smoking status, previous diabetes, previous cardiovascular disease, previous heart failure, previous electro conversion, baseline use of amiodarone, baseline use of thyroid hormones or known previous hypothyroidism 
Appendix Table 1b. Cardiovascular events and all-cause mortality by subclinical thyroid status at baseline in participants according to cardiovascular disease at baseline $(\mathrm{N}=\mathbf{2 3 3 2})$

\begin{tabular}{|c|c|c|c|c|c|c|}
\hline \multirow[t]{2}{*}{ Thyroid Status } & \multicolumn{3}{|c|}{$\begin{array}{c}\text { Subclinical Hyperthyroidism with } \\
\text { TSH }<0.45 \mathrm{mIU} / \mathrm{L}\end{array}$} & \multicolumn{3}{|c|}{$\begin{array}{l}\text { Subclinical Hypothyroidism with TSH 4.5- } \\
19.9 \mathrm{mIU} / \mathrm{L}\end{array}$} \\
\hline & Events/N & $\begin{array}{l}\text { HR }(95 \% \mathrm{Cl}) \\
\text { age/sex- } \\
\text { adjusted }\end{array}$ & $\begin{array}{c}\mathrm{P} \text { for } \\
\text { interaction }\end{array}$ & Events/N & $\begin{array}{c}\text { HR }(95 \% \mathrm{Cl}) \\
\text { age/sex- } \\
\text { adjusted }\end{array}$ & $\begin{array}{c}\mathrm{P} \text { for } \\
\text { interaction }\end{array}$ \\
\hline \multicolumn{7}{|l|}{ Patients with CV-disease } \\
\hline Composite endpoint & $2 / 10$ & $\begin{array}{l}0.84(0.21- \\
3.41)\end{array}$ & 0.633 & $18 / 70$ & $0.89(0.52-1.51)$ & 0.165 \\
\hline HF-events & $1 / 10$ & $\begin{array}{c}0.68(0-09- \\
4.91) \\
\end{array}$ & 0.746 & $7 / 70$ & $0.67(0.31-1.45)$ & 0.444 \\
\hline \multicolumn{7}{|l|}{$\begin{array}{l}\text { Patients without CV- } \\
\text { disease }\end{array}$} \\
\hline Composite endpoint & $3 / 43$ & $\begin{array}{l}0.48(0.15- \\
1.51)\end{array}$ & 0.214 & $18 / 126$ & $1.05(0.65-1.71)$ & 0.869 \\
\hline HF-events & $2 / 43$ & $\begin{array}{c}0.61(0.15- \\
2.50)\end{array}$ & 0.499 & $10 / 126$ & $1.08(0.56-2.08)$ & 0.746 \\
\hline
\end{tabular}

Abbreviations: CV: cardiovascular, HF: heart failure, HR: Hazard Ratio 
Appendix Table 2. Associations between TSH as continuous exposures and cardiovascular events and all-cause mortality in all participants ( $\mathrm{N}=\mathbf{2 3 3 2}$ )

\begin{tabular}{|c|c|c|}
\hline & \multicolumn{2}{|c|}{$\begin{array}{c}\text { Per 1 unit } \\
\text { increase in } \\
\text { TSH }\end{array}$} \\
\hline & $\begin{array}{c}\text { HR }(95 \% \mathrm{Cl}) \\
\text { Age/sex adjusted model }\end{array}$ & $\begin{array}{c}\text { HR }(95 \% \mathrm{Cl}) \\
\text { multivariable model }\end{array}$ \\
\hline Composite endpoint & $1.05(0.99-1.11)$ & $1.05(0.99-1.10)$ \\
\hline Stroke/TIA & $1.03(0.92-1.15)$ & $1.03(0.92-1.14)$ \\
\hline MI & $1.04(0.89-1.21)$ & $1.03(0.89-1.21)$ \\
\hline HF-events & $1.05(0.98-1.13)$ & $1.05(0.98-1.12)$ \\
\hline CV death & $1.06(0.97-1.16)$ & $1.06(0.97-1.16)$ \\
\hline Total Mortality & $1.06(0.98-1.14)$ & $1.06(0.98-1.14)$ \\
\hline
\end{tabular}

Abbreviations: BMI: body mass index, CV: cardiovascular, HF: heart failure, HR: Hazard Ratio, MI: myocardial infarction, TIA: transient ischemic event ${ }^{a}$ adjusted for age, sex, BMI and smoking status 
Appendix Table 3. Cardiovascular events and all-cause mortality by subclinical thyroid status excluding participants with thyroid altering medications at baseline $^{\text {a }}$

\begin{tabular}{|c|c|c|c|c|c|c|c|}
\hline & \multirow{2}{*}{$\begin{array}{c}\text { Euthyroidism with } \\
\text { TSH 0.45-4.49mIU/L } \\
\mathbf{N}=1847 \\
\\
\text { Events }\end{array}$} & \multicolumn{3}{|c|}{$\begin{array}{l}\text { Subclinical Hyperthyroidism with TSH }<0.45 \mathrm{mlU} / \mathrm{L} \\
\qquad \mathrm{N}=33\end{array}$} & \multicolumn{3}{|c|}{$\begin{array}{l}\text { Subclinical Hypothyroidism with TSH 4.5- } \\
\qquad \begin{array}{c}19.9 \mathrm{mlU} / \mathrm{L} \\
\mathrm{N}=153\end{array} \\
\end{array}$} \\
\hline & & Events & $\begin{array}{c}\mathrm{HR}(95 \% \mathrm{Cl}) \\
\text { age/sex adjusted }\end{array}$ & $\begin{array}{c}\mathrm{HR}(95 \% \mathrm{Cl}) \\
\text { multivariable model }^{\mathrm{b}}\end{array}$ & Events & $\begin{array}{c}\mathrm{HR}(95 \% \mathrm{Cl}) \\
\text { age/sex adjusted }\end{array}$ & $\begin{array}{c}\mathrm{HR}(95 \% \mathrm{Cl}) \\
\text { multivariable model }^{\mathrm{b}}\end{array}$ \\
\hline Composite endpoint & 308 & 4 & $0.74(0.27-1.97)$ & $0.75(0.28-2.01)$ & 21 & $0.79(0.51-1.23)$ & $0.79(0.51-1.23)$ \\
\hline Stroke/TIA & 73 & 1 & $0.74(0.10-5.30)$ & $0.75(0.10-5.44)$ & 6 & $0.95(0.41-2-18)$ & $0.95(0.41-2.17)$ \\
\hline HF-events & 178 & 2 & $0.66(0.16-2.65)$ & $0.66(0.16-2.67)$ & 12 & $0.78(0.43-1.40)$ & $0.77(0.43-1.39)$ \\
\hline CV death & 101 & 1 & $0.61(0.08-3.74)$ & $0.61(0.08-4.36)$ & 5 & $0.60(0.24-1.48)$ & $0.61(0.25-1.49)$ \\
\hline Total Mortality & 148 & 2 & $0.80(0.20-3.23)$ & $0.80(0.19-3.22)$ & 11 & $0.89(0.48-1.64)$ & $0.89(0.48-1.64)$ \\
\hline
\end{tabular}

Abbreviations: BMI: body mass index, CV: cardiovascular, HF: heart failure, HR: Hazard Ratio, MI: myocardial infarction, TIA: transient ischemic event ${ }^{a}$ participants with thyroid altering medications at baseline $N=247$; One participant reported to have both thyreostatic medications and thyroid hormones.

${ }^{b}$ Adjusted for age, sex, BMI, smoking status; The euthyroidism group was used as the reference group 
Appendix Table 4. Cardiovascular events and all-cause mortality by subclinical thyroid status (competing risks models) in all participants ( $\mathrm{N}=2332$ )

\begin{tabular}{|c|c|c|}
\hline & $\begin{array}{c}\text { Subclinical Hyperthyroidism with TSH }<\mathbf{0 . 4 5 m I U / L} \\
(\mathbf{N}=\mathbf{5 3})\end{array}$ & $\begin{array}{c}\text { Subclinical Hypothyroidism with TSH 4.5-19.9mIU/L } \\
(\mathbf{N}=\mathbf{1 9 6})\end{array}$ \\
\hline & $\begin{array}{c}\text { SHR }(95 \% \mathrm{Cl}) \\
\text { age/sex adjusted }\end{array}$ & $\begin{array}{c}\text { SHR }(95 \% \mathrm{Cl}) \\
\text { age/sex adjusted }\end{array}$ \\
\hline Composite endpoint & $0.57(0.24-1.36)$ & $0.99(0.69-1.43)$ \\
\hline Stroke/TIA & $0.49(0.07-3.56)$ & $0.86(0.39-1.87)$ \\
\hline MI & $1.99(0.48-8.23)$ & $1.48(0.63-3.48)$ \\
\hline HF-events & $0.64(0.21-1.92)$ & $0.87(0.52-1.43)$ \\
\hline CV death & $0.36(0.05-2.69)$ & $1.07(0.57-2.01)$ \\
\hline
\end{tabular}

Abbreviations: CV: cardiovascular, HF: heart failure, HR: Hazard Ratio, MI: myocardial infarction, SHR: Subhazard ratio, TIA: transient ischemic event ${ }^{a}$ adjusted for age, sex, BMI, smoking status 
Appendix Table 5. Cardiovascular events and all-cause mortality by fT4 as a continuous exposure at baseline

\begin{tabular}{|c|c|c|}
\hline \multirow[t]{2}{*}{ Thyroid Status } & \multicolumn{2}{|c|}{$\begin{array}{l}\text { Per } 5 \text { unit } \\
\text { increase in } \\
\text { fT4 }\end{array}$} \\
\hline & $\begin{array}{c}\mathrm{HR}(95 \% \mathrm{Cl}) \\
\text { age/sex-adjusted }\end{array}$ & $\begin{array}{c}\mathrm{HR}(95 \% \mathrm{Cl}) \\
\text { Multivariable } \\
\text { adjusted }^{a}\end{array}$ \\
\hline \multicolumn{3}{|c|}{ All Euthyroid Participants ( $N=2004$ ) } \\
\hline Composite endpoint & $1.16(1.10-1.28)^{\mathrm{b}}$ & $1.16(1.10-1.28)^{b}$ \\
\hline Stroke/TIA & $0.95(0.66-1.34)$ & $0.95(0.66-1.34)$ \\
\hline$M I$ & $0.95(0.73-1.40)$ & $1.00(0.70-1.40)$ \\
\hline HF-events & $1.22(1.10-1.34)^{\mathrm{b}}$ & $1.22(1.16-1.34)^{b}$ \\
\hline CV death & $1.10(1.05-1.22)^{\mathrm{b}}$ & $1.10(1.05-1.22)^{b}$ \\
\hline Total Mortality & $1.10(1.00-1.16)^{\mathrm{b}}$ & $1.10(1.00-1.22)^{b}$ \\
\hline \multicolumn{3}{|c|}{$\begin{array}{l}\text { Excluding euthyroid participants with amiodarone } \\
\text { at baseline ( } N=1696)\end{array}$} \\
\hline Composite endpoint & $1.16(1.10-1.28)^{\mathrm{b}}$ & $1.19(1.10-1.27)^{\mathrm{b}}$ \\
\hline Stroke/TIA & $1.05(0.86-1.28)$ & $1.05(0.86-1.27)$ \\
\hline$M I$ & $1.00(0.77-1.40)$ & $1.05(0.77-1.40)$ \\
\hline HF-events & $1.22(1.10-1.28)^{\mathrm{b}}$ & $1.22(1.16-1.34)^{b}$ \\
\hline CV death & $1.10(0.95-1.22)$ & $1.10(1.00-1.21)^{\mathrm{b}}$ \\
\hline Total Mortality & $1.10(1.00-1.16)^{b}$ & $1.10(1.05-1.16)^{b}$ \\
\hline \multicolumn{3}{|c|}{$\begin{array}{l}\text { Excluding euthyroid participants with thyroid } \\
\text { altering medications at baseline } \\
\text { and follow up ( } N=1829)\end{array}$} \\
\hline Composite endpoint & $1.16(1.10-1.28)^{\mathrm{b}}$ & $1.16(1.05-1.27)^{\mathrm{b}}$ \\
\hline Stroke/TIA & $0.82(0.53-1.28)$ & $0.77(0.52-1.22)$ \\
\hline$M I$ & $0.95(0.62-1.54)$ & $0.95(0.62-1.53)$ \\
\hline
\end{tabular}




\begin{tabular}{|c|c|c|}
\hline HF-events & $1.22(1.10-1.28)^{\mathrm{b}}$ & $1.22(1.10-1.34)^{\mathrm{b}}$ \\
\hline CV death & $1.10(0.95-1.22)$ & $1.10(0.95-1.22)$ \\
\hline Total Mortality & $1.10(0.95-1.16)$ & $1.05(0.95-1.22)$ \\
\hline
\end{tabular}

Abbreviations: BMI: body mass index, CV: cardiovascular, HF: heart failure, HR: Hazard Ratio, MI: myocardial infarction, TIA: transient ischemic event ${ }^{a}$ adjusted for age, sex, BMI, smoking status; ${ }^{b} p<0.05$ 
Appendix Table 6. Baseline characteristics of included participants according to fT4 quintiles ( $N=2332$ )

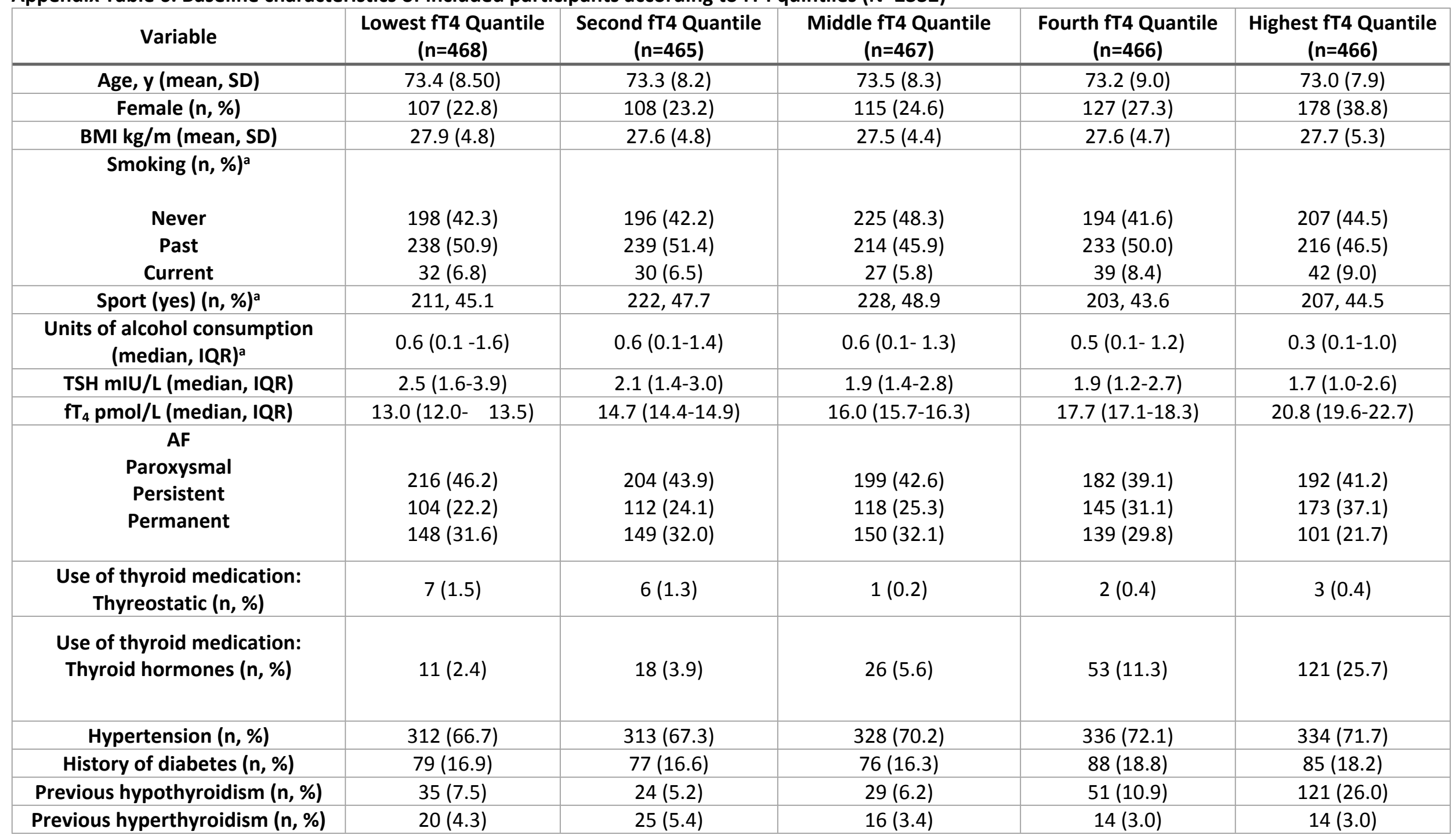




\begin{tabular}{|c|c|c|c|c|c|}
\hline History of $\mathrm{CVD}^{\mathrm{b}}(\mathrm{n}, \%)$ & $139(29.7)$ & $161(34.6)$ & $139(29.8)$ & $168(36.1)$ & $176(37.8)$ \\
\hline Baseline statin $(n, \%)$ & $208(44.4)$ & $238(51.2)$ & $226(48.4)$ & $235(50.4)$ & $237(50.9)$ \\
\hline Baseline ACEI (n, \%) & $130(27.8)$ & $149(32.0)$ & $143(30.6)$ & 163 (34.9) & 151 (32.4) \\
\hline Baseline ARBs (n, \%) & $125(26.7)$ & $131(28.2)$ & $148(31.7)$ & $149(32.0)$ & $168(36.1)$ \\
\hline
\end{tabular}

Abbreviations: ACEIs: Angiotensin converting enzymes, AF: atrial fibrillation, ARBs: Angiotensin II receptor blockers, BMI: body mass index CVD: cardiovascular disease; ${ }^{a} n=2$ missing; ${ }^{b} \mathrm{CVD}$ defined as previous myocardial infarction, bypass, peripheral arterial disease; ${ }^{c} n=1$ missing 
Appendix Table 7. Cardiovascular events and all-cause mortality by fT4 quintiles at baseline in euthyroid participants excluding participants with amiodarone at baseline*

\begin{tabular}{|c|c|c|c|c|c|c|c|c|c|c|c|c|c|c|c|}
\hline \multirow[t]{2}{*}{$\begin{array}{c}\text { FT4 } \\
\text { Quintil } \\
\text { es IQR }\end{array}$} & \multicolumn{3}{|c|}{$\begin{array}{c}12.0-13.5 \\
N=375\end{array}$} & \multicolumn{3}{|c|}{$\begin{array}{c}14.4-15.0 \\
N=394\end{array}$} & \multicolumn{3}{|c|}{$\begin{array}{c}15.7-16.3 \\
N=381\end{array}$} & \multicolumn{3}{|c|}{$\begin{array}{c}17.2-18.3 \\
N=342\end{array}$} & \multicolumn{3}{|c|}{$\begin{array}{c}19.7-22.8 \\
N=204\end{array}$} \\
\hline & $\begin{array}{l}\text { Even } \\
\text { ts }\end{array}$ & $\begin{array}{c}\text { HR }(95 \% \mathrm{Cl}) \\
\text { age/sex- } \\
\text { adjusted }\end{array}$ & $\begin{array}{l}\mathrm{HR}(95 \% \\
\mathrm{Cl}) \\
\text { multivaria } \\
\text { ble model } \\
\quad \text { a }\end{array}$ & $\begin{array}{l}\text { Even } \\
\text { ts } \\
\mathrm{N}\end{array}$ & $\begin{array}{c}\text { HR }(95 \% \mathrm{Cl}) \\
\text { age/sex- } \\
\text { adjusted }\end{array}$ & $\begin{array}{l}\mathrm{HR}(95 \% \\
\mathrm{Cl}) \\
\text { multivaria } \\
\text { ble model } \\
\underset{\text { a }}{ }\end{array}$ & $\begin{array}{l}\text { Even } \\
\text { ts } \\
\mathrm{N}\end{array}$ & $\begin{array}{c}\mathrm{HR} \\
(95 \% \\
\mathrm{Cl}) \\
\text { age/se } \\
\text { x- } \\
\text { adjust } \\
\text { ed }\end{array}$ & $\begin{array}{l}\mathrm{HR}(95 \% \\
\mathrm{Cl}) \\
\text { multivaria } \\
\text { ble model } \\
\underset{a}{\mathrm{a}}\end{array}$ & $\begin{array}{l}\text { Even } \\
\text { ts } \\
\mathrm{N}\end{array}$ & $\begin{array}{c}\text { HR }(95 \% \mathrm{Cl}) \\
\text { age/sex- } \\
\text { adjusted }\end{array}$ & $\begin{array}{c}\text { HR }(95 \% \\
\mathrm{Cl}) \\
\text { multivaria } \\
\text { ble model } \\
\text { a }\end{array}$ & $\begin{array}{c}\text { Even } \\
\text { ts } \\
\mathrm{N}\end{array}$ & $\begin{array}{c}\mathrm{HR} \\
(95 \% \\
\mathrm{Cl}) \\
\text { age/se } \\
\mathrm{x}- \\
\text { adjust } \\
\text { ed }\end{array}$ & $\begin{array}{l}\text { HR (95\% } \\
\text { Cl) } \\
\text { multivaria } \\
\text { ble model } \\
\text { a }\end{array}$ \\
\hline $\begin{array}{l}\text { Compos } \\
\text { ite } \\
\text { endpoin } \\
t\end{array}$ & 57 & $\begin{array}{c}1.08(0.75- \\
1.55)\end{array}$ & $\begin{array}{c}1.09 \\
(0.76- \\
1.57)\end{array}$ & 59 & $\begin{array}{c}0.99(0.69- \\
1.42)\end{array}$ & $\begin{array}{c}1.01 \\
(0.70- \\
1.44)\end{array}$ & 60 & 1.00 & 1.00 & 71 & $\begin{array}{c}1.53(1.08- \\
2.15)^{b}\end{array}$ & $\begin{array}{c}1.53 \\
(1.08- \\
2.16)^{b}\end{array}$ & 44 & $\begin{array}{c}1.76 \\
(1.19- \\
2.61)^{b}\end{array}$ & $\begin{array}{l}1.79 \\
(1.21- \\
2.67)^{b}\end{array}$ \\
\hline $\begin{array}{c}\text { HF- } \\
\text { events }\end{array}$ & 27 & $\begin{array}{c}0.91(0.55- \\
1.51)\end{array}$ & $\begin{array}{c}0.92 \\
(0.55- \\
1.53) \\
\end{array}$ & 38 & $\begin{array}{c}1.16(0.73- \\
1.85)\end{array}$ & $\begin{array}{c}1.18 \\
(0.74- \\
1.88) \\
\end{array}$ & 33 & 1.00 & 1.00 & 42 & $\begin{array}{c}1.63(1.03- \\
2.57)^{b}\end{array}$ & $\begin{array}{c}1.63 \\
(1.03- \\
2.57) \mathrm{b}\end{array}$ & 27 & $\begin{array}{c}1.81 \\
(1.08- \\
3.02)^{b}\end{array}$ & $\begin{array}{r}1.88 \\
(1.12- \\
3.15)^{b} \\
\end{array}$ \\
\hline $\begin{array}{c}\text { Total } \\
\text { Mortali } \\
\text { ty }\end{array}$ & 27 & $\begin{array}{c}1.06(0.63- \\
1.79)\end{array}$ & $\begin{array}{c}1.07 \\
(0.63- \\
1.80)\end{array}$ & 35 & $\begin{array}{c}1.25(0.76- \\
2.04)\end{array}$ & $\begin{array}{l}1.25 \\
(0.76- \\
2.04)\end{array}$ & 29 & 1.00 & 1.00 & 35 & $\begin{array}{c}1.56(0.95- \\
2.54)\end{array}$ & $\begin{array}{c}1.53 \\
(0.93- \\
2.52)\end{array}$ & 19 & $\begin{array}{c}1.69 \\
(0.94- \\
3.04)\end{array}$ & $\begin{array}{c}1.69 \\
(0.94- \\
3.04)\end{array}$ \\
\hline
\end{tabular}

*Participants on amiodarone N=308; Abbreviations: BMI: body mass index, CV: cardiovascular, HF: heart failure, HR: Hazard Ratio, MI: myocardial infarction, TIA: transient ischemic event

${ }^{a}$ adjusted for: age, sex, BMI, smoking status ${ }^{b} p<0.05$ 


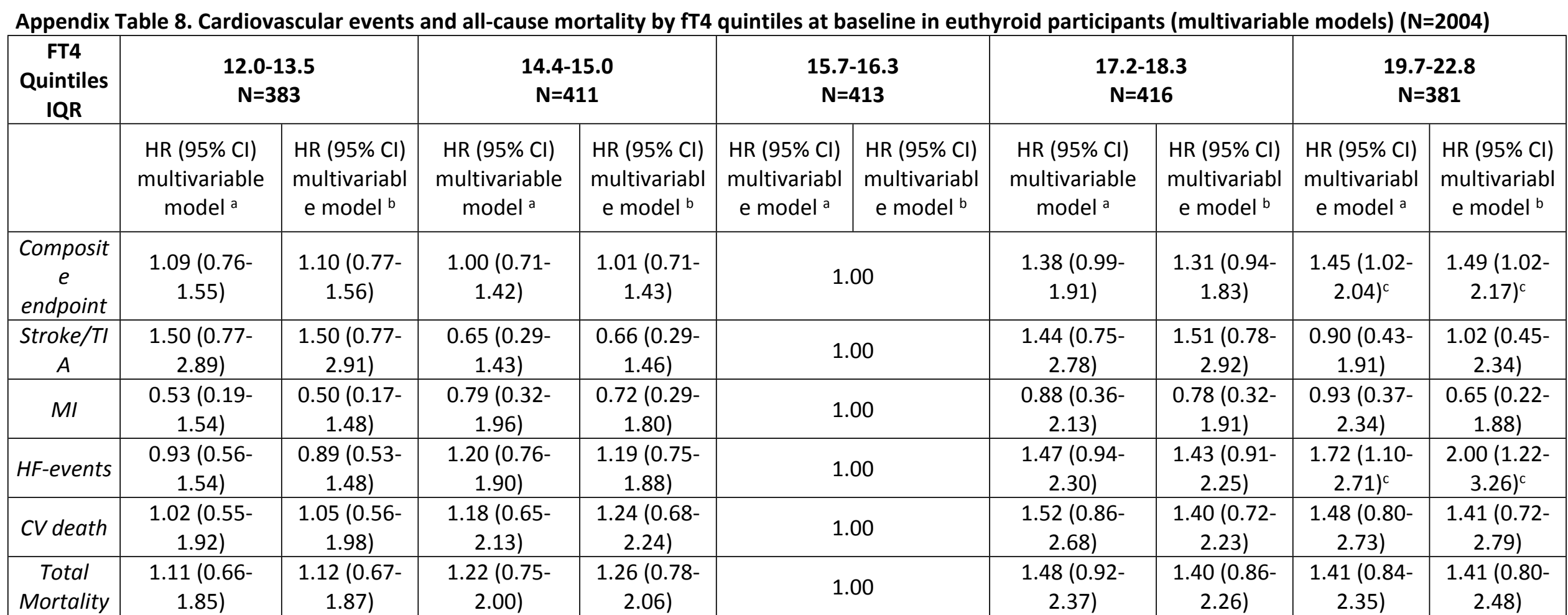

Abbreviations: BMI: body mass index, CV: cardiovascular, HF: heart failure, HR: Hazard Ratio, MI: myocardial infarction, TIA: transient ischemic event; For number of events see Table 3;

${ }^{a}$ adjusted for: age, sex, BMI, smoking status badjusted for: age, sex, BMI, smoking status, previous cardiovascular disease, previous heart failure, previous electroconversion, baseline use of amiodarone, baseline use of thyroid hormones, previous hypothyroidism ${ }^{c} p<0.05$ 
Appendix Table 9. Cardiovascular events by fT4 quintiles at baseline in euthyroid participants excluding participants with thyroid altering medications at baseline and during follow-up ( $\mathrm{N}=1829)^{*}$

\begin{tabular}{|c|c|c|c|c|c|c|c|c|c|c|}
\hline \multirow[t]{2}{*}{ FT4 Quintiles IQR } & \multicolumn{2}{|r|}{$\begin{array}{c}12.0-13.5 \\
N=372\end{array}$} & \multicolumn{2}{|r|}{$\begin{array}{c}14.4-15.0 \\
N=396\end{array}$} & \multicolumn{2}{|r|}{$\begin{array}{c}15.7-16.3 \\
N=393\end{array}$} & \multicolumn{2}{|r|}{$\begin{array}{c}17.2-18.3 \\
N=376\end{array}$} & \multicolumn{2}{|r|}{$\begin{array}{c}19.7-22.8 \\
N=292\end{array}$} \\
\hline & Events & $\begin{array}{c}\mathrm{HR}(95 \% \mathrm{Cl}) \\
\text { age/sex-adjusted }\end{array}$ & Events & $\begin{array}{c}\mathrm{HR}(95 \% \mathrm{Cl}) \\
\text { age/sex-adjusted }\end{array}$ & Events & $\begin{array}{c}\text { HR (95\% Cl) } \\
\text { age/sex-adjusted }\end{array}$ & Events & $\begin{array}{c}\mathrm{HR}(95 \% \mathrm{Cl}) \\
\text { age/sex-adjusted }\end{array}$ & Events & $\begin{array}{c}\mathrm{HR}(95 \% \mathrm{Cl}) \\
\text { age/sex-adjusted }\end{array}$ \\
\hline Composite endpoint & 58 & $1.11(0.78-1.59)$ & 62 & $1.06(0.74-1.51)$ & 61 & 1.00 & 71 & $1.39(0.98-1.96)$ & 52 & $1.36(0.94-1.97)$ \\
\hline HF-events & 27 & $1.03(0.61-1.73)$ & 39 & $1.36(0.84-2.19)$ & 30 & 1.00 & 43 & $1.72(1.08-2.75)^{\mathrm{a}}$ & 35 & $1.83(1.12-2.98)^{a}$ \\
\hline
\end{tabular}

*Participants with thyroid altering medications at baseline $(N=157)$ and during follow-up ( $N=18)$; Abbreviations: HF: Heart Failure, HR: Hazard Ratio; ${ }^{a} p<0.05$ 
Appendix Table 10. Cardiovascular events and all-cause mortality by fT4 quintiles (competing risks models) in euthyroid participants ( $\mathrm{N}=2004)$

\begin{tabular}{|c|c|c|c|c|c|}
\hline FT4 Quintiles IQR & $\mathbf{1 2 . 0 - 1 3 . 5}$ & $\mathbf{1 4 . 4 - 1 5 . 0}$ & $\mathbf{1 5 . 7 - 1 6 . 3}$ & $\mathbf{1 7 . 2 - 1 8 . 3}$ & $\mathbf{1 9 . 7 - 2 2 . 8}$ \\
\hline & $\begin{array}{c}\text { SHR (95\% CI) } \\
\text { age/sex adjusted }\end{array}$ & $\begin{array}{c}\text { SHR (95\% CI) } \\
\text { age/sex adjusted }\end{array}$ & $\begin{array}{c}\text { SHR (95\% CI) } \\
\text { age/sex adjusted }\end{array}$ & $\begin{array}{c}\text { SHR (95\% CI) } \\
\text { age/sex adjusted }\end{array}$ & $\begin{array}{c}\text { SHR (95\% CI) } \\
\text { age/sex adjusted }\end{array}$ \\
\hline Composite endpoint & $1.07(0.75-1.52)$ & $0.98(0.69-1.39)$ & 1.00 & $1.37(0.99-1.91)$ & $1.46(1.03-2.06)^{\mathrm{a}}$ \\
\hline Stroke/TIA & $1.49(0.77-2.90)$ & $0.64(0.29-1.42)$ & 1.00 & $1.42(0.74-2.74)$ & $0.90(0.43-1.92)$ \\
\hline MI & $0.54(1.19-1.55)$ & $0.77(0.31-1.92)$ & 1.00 & $0.88(0.36-2.14)$ & $0.90(0.36-2.26)$ \\
\hline HF-events & $0.92(0.55-1.53)$ & $1.19(0.75-1.90)$ & 1.00 & $1.45(0.93-2.27)$ & $1.68(1.07-2.64)^{\mathrm{a}}$ \\
\hline CV death & $1.01(0.54-1.88)$ & $1.15(0.63-2.05)$ & 1.00 & $1.50(0.85-2.62)$ & $1.54(0.83-2.85)$ \\
\hline
\end{tabular}

Abbreviations: CV:cardiovascular, HF: heart failure, MI: myocardial infarction, SHR: Subhazard Ratio, TIA: transient ischemic event ${ }^{a} p<0.05$ 
Appendix Table 11. Association between subclinical thyroid status and AF-progression in all participants ( $\mathrm{N}=2332$ )

\begin{tabular}{|c|c|c|c|c|c|}
\hline & \multirow{2}{*}{$\begin{array}{c}\text { Euthyroidism with TSH 0.45- } \\
4.49 \mathrm{mIU} / \mathrm{L} \\
\\
\text { Events } / \mathrm{N}\end{array}$} & \multicolumn{2}{|c|}{$\begin{array}{c}\text { Subclinical Hyperthyroidism with TSH } \\
<0.45 \mathrm{mIU} / \mathrm{L}\end{array}$} & \multicolumn{2}{|c|}{$\begin{array}{c}\text { Subclinical Hypothyroidism with TSH } 4.5 \\
19.9 \mathrm{mIU} / \mathrm{L}\end{array}$} \\
\hline & & Events/N & $\begin{array}{c}\mathrm{HR}(95 \% \mathrm{Cl}) \\
\text { age/sex adjusted }\end{array}$ & Events/N & $\begin{array}{c}\mathrm{HR}(95 \% \mathrm{Cl}) \\
\text { age/sex adjusted }\end{array}$ \\
\hline Clinical AF Progression & $247 / 2004$ & $8 / 53$ & $1.08(0.53-2.18)$ & $24 / 196$ & $1.05(0.69-1.60)$ \\
\hline $\begin{array}{l}\text { Pharmacological AF } \\
\text { Progression }^{\mathrm{a}}\end{array}$ & $205 / 1696$ & $8 / 49$ & $1.24(0.61-2.51)$ & $18 / 133$ & $1.22(0.75-1.99)$ \\
\hline
\end{tabular}

Abbreviations: HR: Hazard Ratio ${ }^{a}$ excluding participants with amiodarone at baseline $(n=407)$ 